\title{
Alternative Energy for Higher Education
}

Final Report

Funded by:

Department of Energy, Energy Efficiency and Renewable Energy

DE-EE0000341

Michael Cherney, Principal Investigator

mcherney@creighton.edu

402-280-3039

Creighton University

2500 California Plaza

Omaha, NE 68178 


\section{Executive Summary}

This project provides educational opportunities creating both a teaching facility and center for public outreach. The facility is the largest solar array in Nebraska. It was designed to allow students to experience a variety of technologies and provide the public with opportunities for exposure to the implementation of an alternative energy installation designed for an urban setting. The project integrates products from 5 panel manufacturers (including monocrystalline, polycrystalline and thin film technologies) mounted on both fixed and tracking structures. The facility uses both micro and high power inverters. The majority of the system was constructed to serve as an outdoor classroom where panels can be monitored, tested, removed and replaced by students. As an educational facility it primarily serves students in the Creighton University and Metropolitan Community College, but it also provides broader educational opportunities.

The project includes a real-time "dashboard" and a historical database of the output of individual inverters and the corresponding meteorological data for researcher and student use. This allows the evaluation of both panel types and the feasibility of installation types in a region of the country subject to significant temperature, wind and precipitation variation.

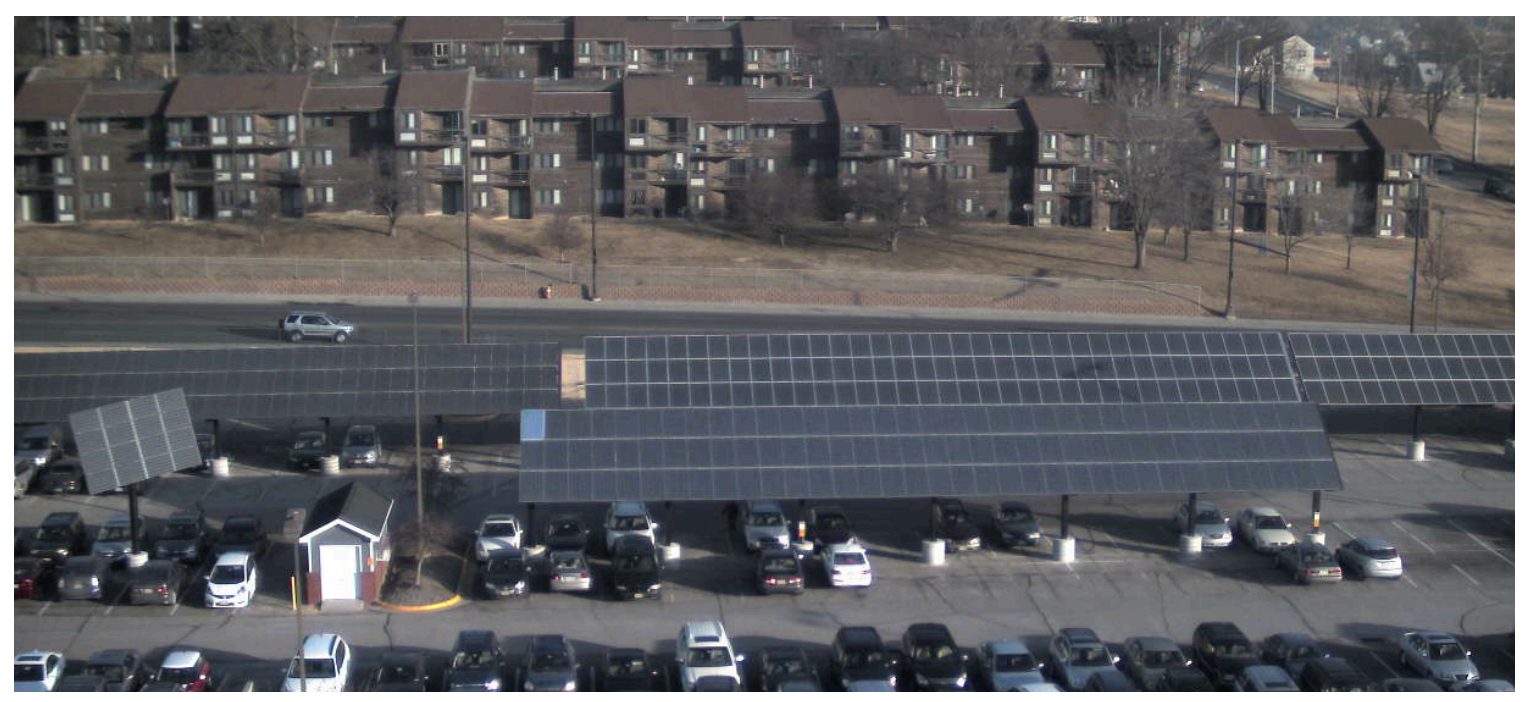

Figure 1. The Burt Street Parking Lot Array is the largest solar array in Nebraska. It serves as the outdoor classroom. More than 300 people have visited the facility. Signs of student work on the array are visible on close inspection.

\section{Facilities Developed}

The solar facilities at Creighton University were developed primarily as a teaching tool and community education resource. The collectors and associated power inverting electronics include a broad spectrum of commercially available architectures chosen as part of student-oriented research project to evaluate the 
performance of these renewable energy systems in the climate of Nebraska. The solar arrays have a total output of $110 \mathrm{~kW}$. The two largest parts of the system are located in a lower cost rooftop installation on the university fitness center (shown in Figure 2) and a large array of conventional panels built over a parking lot (shown in Figure 1).

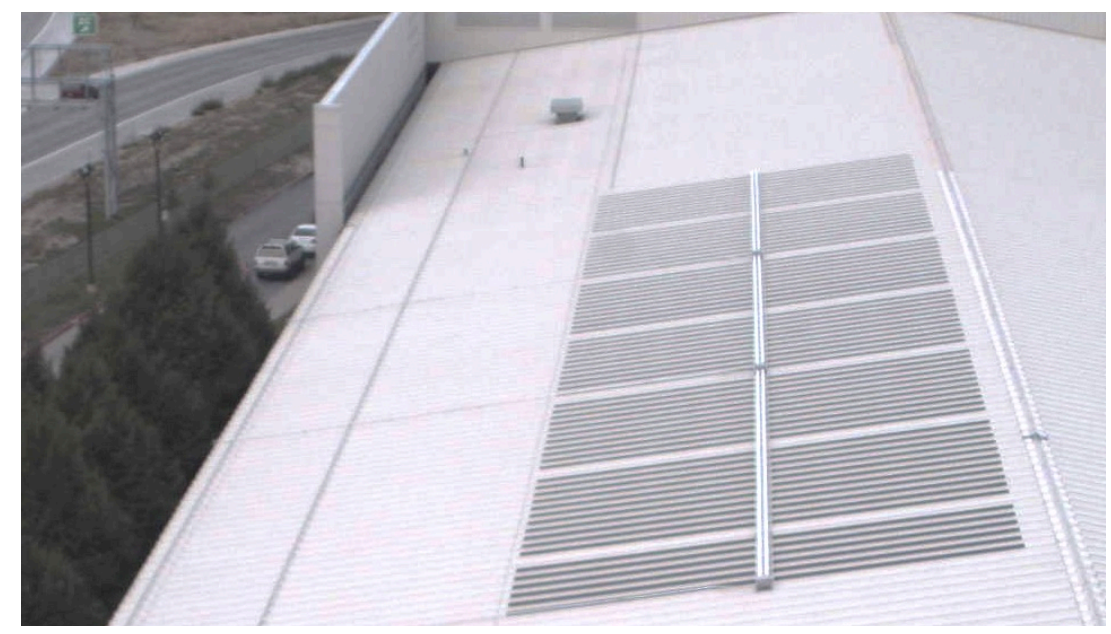

Figure 2. The thin film array on the Kiewit Fitness Center rooftop is visible from I-480. Although not student accessible, its installation was filmed for training purposes.

Mounted with a southern exposure and a 5 degree inclination, this recreation center system consists of multiple strips of flexible photovoltaic laminate arrays totaling 143 individual panels (each approximately $23 \mathrm{sq}$. $\mathrm{ft}$ ). The laminate is manufactured by Uni-Solar (PVL-144) and the system is partitioned into three sections which are independently converted to AC power using three power inverters manufactured by Fronius (IG-Plus 7.5-1 Uni Inverter).

The Burt Street site (shown in Figure 1) contains the broadest variety of solar collection architectures and power inversion technologies. Together with an integrated weather monitoring station, it was designed to serve as the main laboratory for student training and research activities. Located at this site are:

- One Watt-Sun (AZ-225) tracking array composed of 16 Sanyo (215N HIT) panels. Each panel is connected to an Enphase (M210) microinverter. The tracking array is capable of supplying $3.4 \mathrm{~kW}$

- 6 Sanyo (215N HIT) panels (each 13.5 sq. ft. area, $215 \mathrm{~W}$ ) connected to a Fronius (IG Plus 3.0-1 UniInverter) inverter with a power output of $1.3 \mathrm{~kW}$.

- 32 Sanyo (215N HIT) panels supplying a Fronius (IG Plus 7.5-1 Unilnverter) inverter with net power output of $6.9 \mathrm{~kW}$.

- 105 Evergreen Solar (ES-A-210) panels (each 17 sq. ft. area, $210 \mathrm{~W}$ ) feeding 3 Fronius (IG Plus 7.5-1 UniInverter) inverters with net power output of $22 \mathrm{~kW}$.

- 33 Sharp (ND-U224) panels connected to a Fronius (IG Plus 7.5-1 UniInverter) inverter with a net power output of $7.4 \mathrm{~kW}$. 
- 33 Schott (Poly 220) panels (18 sq. ft. area, 220 W) feeding a Fronius (IG Plus 7.5-1 UniInverter) inverter with a net power output of $7.3 \mathrm{~kW}$

- 66 Sanyo (215N HIT) panels each feeding an Enphase (M210) microinverter for a total power of $14 \mathrm{~kW}$.

- 72 Sharp (ND-U224) panels connected to Enphase (M210) microinverters with a total power output of $16 \mathrm{~kW}$.

- 72 Schott (Poly 220) panels feeding Enphase (M210) microinverter with a net power output of $16 \mathrm{~kW}$.

A website (green.creighton.edu) continuously displays the system output and provides educational materials.

\section{Review of Project Objectives}

We believe all project objectives were met.

The project was designed to develop the educational and research platform for college students and faculty from Creighton University and other institutions. The project serves as a learning facility for students in the Energy Technology Program at Creighton University and the Sustainable Energy Program Metropolitan Community College. Approximately 50 students from these programs have already used the facility. To provide students with a broad experience the Burt Street array (shown in Figure 1) includes panels from four different manufacturers with both panel-mounted microinverters and inverters centralized in the hut.

The project was created to educate the populace on photovoltaic systems through demonstration and awareness. Information on costs, construction and maintenance is shared with local businesses that are considering opportunities for solar production. The largest solar array in Nebraska was constructed in an urban setting where parking is at a premium. The project was intended to repurpose only 2 parking spaces. The array's support structure was unique for the north central region of the country with its carport design. More than 300 individuals have toured the array. Panels were intentionally located near major roadways where they are conspicuous. By conscious decision, the project contains no fencing so the public can walk (and park) under the panels. Inverters for the thin film array situated on the south-facing roof of the student recreation center were located so they are visible to basketball court and jogging track users. A set of web pages (green.creighton.edu) was also created with educational tutorials and webcam views of the facility. This link is included on the Omaha Public Power District's website as part of its efforts to educate the customer base on solar energy and, where appropriate, expand solar production to private businesses. Presentations targeting area business people have addressed issues of project scope, project management and the economics of the Creighton solar arrays in the context of current net metering laws. To give people a sense of the scope of the installation, a real time power production data are visible continuously on campus displays and from a web link. To provide support for future 
developments and project planning, a database of historical power production is available on an inverter-by-inverter basis along with meteorological conditions.

The project supplies about $4 \%$ of the campus' electrical needs during a sunny day. Data from the first year of operation showed the facility produced slightly more than had been projected from PVWATTS tables. Because Nebraska's metering law favors production that does not exceed usage, all production is routed into the main campus.

\section{Review of Project Tasks}

We believe that all project tasks were successfully completed.

The project was intended to be a physical tool to teach members of the learning community about power generation and collection. Students evaluated panel types (See Figure 3.) and made recommendations for panel layout and construction. Engineers studied the roof structural conditions for thin film installation. The roof Engineers, faculty and facilities personnel studied array location and created a site plan. Features of the plan included products from a variety of manufacturers to provide the student users and installers familiarity with a number of technologies. The layout strongly favored public visibility of the project. The only location that would not be directly accessible to students would be the roof-mounted thin film array.

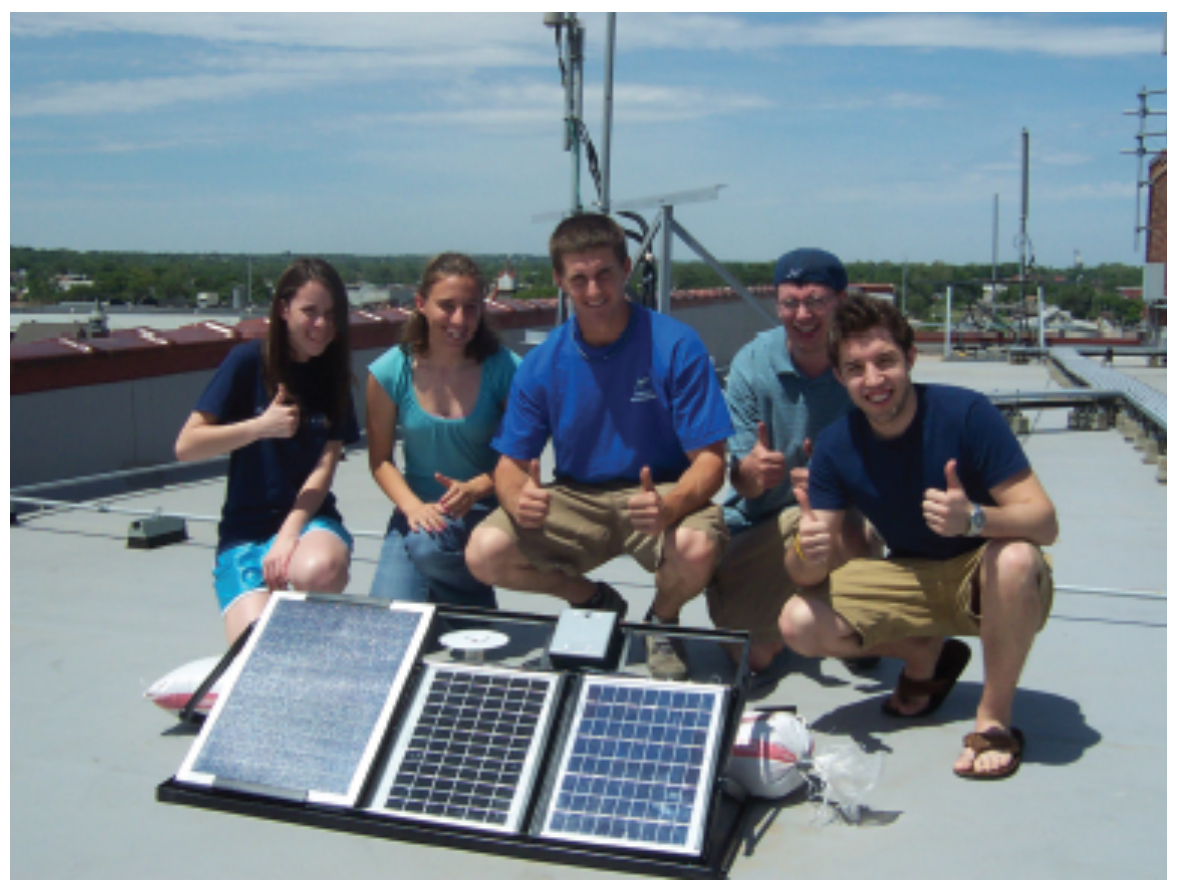

Figure 3. Students study panel types at a rooftop test installation. Early experience with safety regulations in this type of learning environment encouraged the construction of a student accessible array nearer to ground level. 
Construction documents were developed by engineers based on the proposed layout. Nebraska's climate required that special consideration be given to wind and snow loading given the inclination of the carport style arrays. This was also a new exercise in permitting for city authorities. The building code exceptions granted to Creighton became the guidelines for the drafting of new city ordinances better accommodating renewable power generation in downtown Omaha.

Teaching tools were developed and made available on the program website. These include web-based tutorials and a dashboard for real-time display of collector output. Courses at Creighton University and Metropolitan Community College regularly make use of the facility. Students are able to gain installation and maintenance experience, access production data for correlation studies and experiment with adapting the array. The use of the array has been offered to various regional entities as both a training facility and showcase. Handouts and "souvenir" items were created for distribution to visitors. A large portable interactive display incorporating the original test panels was created and has been in use at community events with a renewable energy theme. Regular meetings with representatives of the Omaha Public Power District have insured that the educational materials produced are of service to a larger community.

Adhesive thin film collectors were mounted on the roof of the campus recreation center by electrical contractors. This work was filmed for training purposes. Contractors also installed trackers in the Burt Street parking lot and near the campus performing arts center. (This also provided the first such installation experiences for local electrical workers.)

The large fixed panel solar array was built to serve as an "outdoor classroom". (This array can be seen in Figure 1.) Solar panels and inverters can be periodically installed (and uninstalled) by students involved in the Creighton Energy Technology Program and other training programs in the Omaha area. To foster student training design features of the array include panels from multiple manufacturers (including both monocrystalline and polycrystalline materials with differing current-voltage characteristics), modular electrical components for the isolation of specific portions of the array, redundant disconnects for operational safety, multiple inverter sizes using 2 types of inverter technologies, a modular panel racking system for the simple retro-fit and interchange of panels and technologies, overhead pathways for wiring for easy access, multiple data acquisition gateways for system observation, simple inverter user interfaces for ease in understanding system operating characteristics, and internet accessibility of voltage and current output. A student is shown working on the array in Figure 4.

A weather station was installed in the Burt Street parking lot next to the array. Data from this weather station is stored in the inverter database to allow correlations with the inverter output to be studied. Sky cover information is available from webcams. 


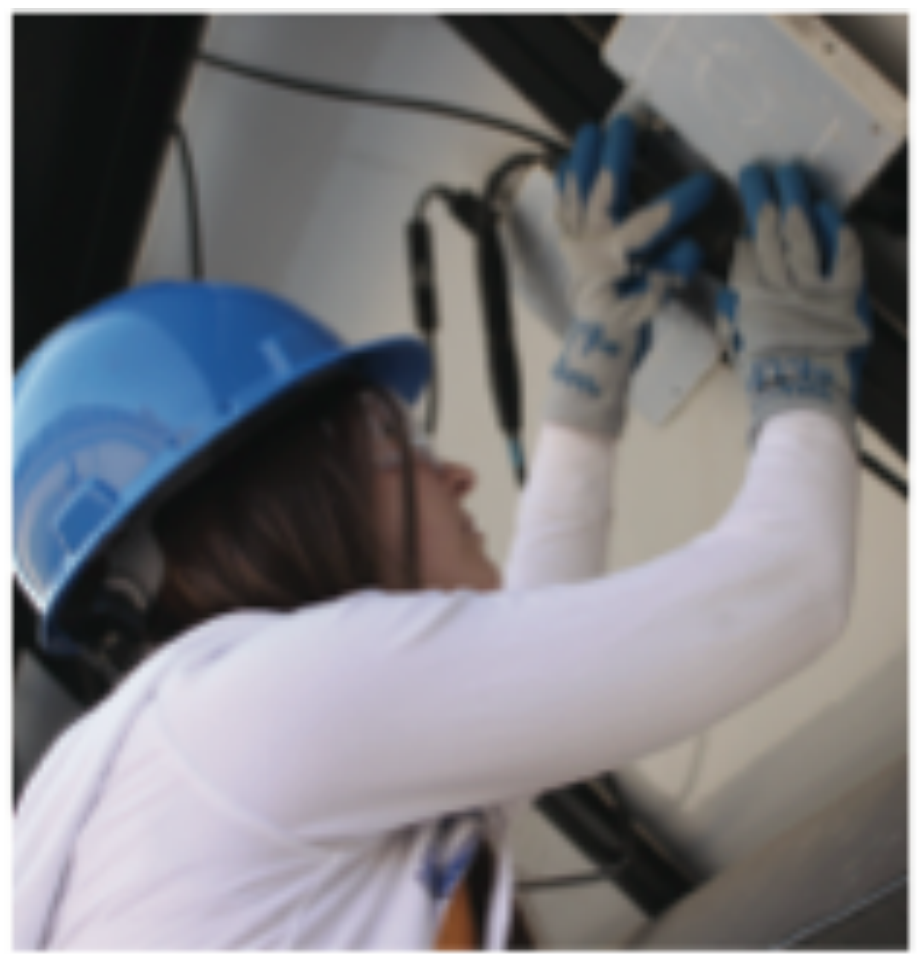

Figure 4. Creighton student Rachel Ketchmark works from a scissors lift on a panelmounted microinverter that is part of the "outdoor classroom".

The commissioning of the system has been completed. The amount and quality of power generated has been studied. Annual energy output from the array has been measured and it slightly exceeded that projected on the basis of manufacturer specifications and expected number of sunlight hours. The sine wave output of the system measured and it showed a better signal quality (less noise) than the grid into which it was being fed.

This report will complete the deliverables and reporting from the project.

\section{Training and Professional Development Opportunities}

Investment in this facility has been leveraged by the establishment of the Energy Technology Program at Creighton University. This Science, Technology, Engineering and Mathematics program developed with resources outside this grant uses novel pedagogical methods to learn energy science in an interdisciplinary and projectbased fashion. It also considers the human and social aspects of energy issues. The program is in its second semester and makes regular use of the "outdoor classroom" and inverter database as part of the curriculum. The program is described in more detail at the website energy.creighton.edu. 
When this project was initially started there was no technical training related to solar energy available in the region. At an early point in the project's history Metropolitan Community College (MCC) began a program in sustainable energy. It was decided that Creighton would open its facilities to MCC students. The Creighton facility currently services a set of introductory technical solar courses that were created at MCC. Figure 5 shows the Creighton solar array being used a training facility.

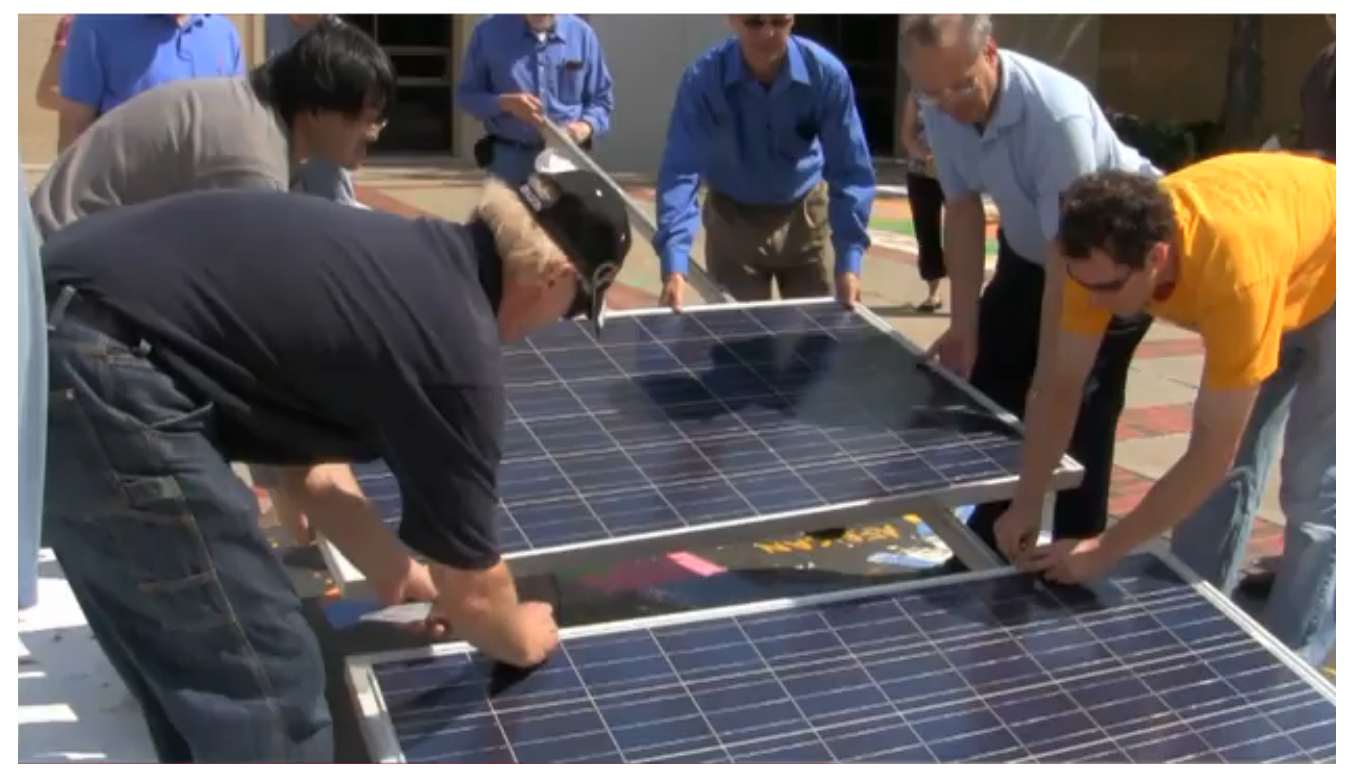

Figure 5. Metropolitan Community College students working on panel installation at the Creighton facility.

\section{Dissemination of Project Work / Outreach}

The project has been presented to numerous community groups from the boy scouts to project managers. Over 300 individuals have toured the Creighton solar array.

The project is fulfilling its role as a working system that the Omaha Public Power District can point to. The Creighton facility has taken on greater significance in regional public awareness of solar energy potential as the result of a major hailstorm that severely damaged the Omaha Public Power District's Renewable Resources Demonstration Facility in the summer of 2011.

Educational materials from the project website have received attention. They have been requested and linked by other sites. A non-profit organization plans to translate a large portion of the web materials providing multilingual access to the materials produced for this project. 
The following more formal presentations were also made:

Eric Hauger, Daniel Blair, Joseph Brewer

A Study of the Solar Capabilities of the Nebraska Climate and Possible Photovoltaic Solutions

Nebraska Academy of Sciences (Lincoln, April 2009)

Eric Hauger

A Comparison by Manufacturer of Solar Panel Output

Creighton University Physics Seminar (Omaha, October 2011)

Data from the Creighton facility is being made available to local businesses.

Historical data is being used to study the proposed development of a similar facility at the Omaha's Henry Doorly Zoo. Real time production data is made available to the Omaha Public Power District. Operational experience on topics from component reliability to the mitigation of snow buildup on the panels is being shared. 